\title{
The vertical distribution of the Venus NO nightglow: limb profiles inversion and one-dimensional modeling
}

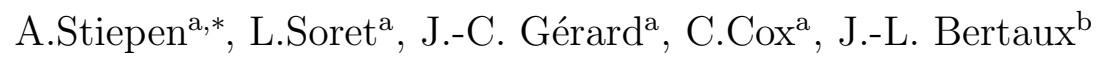 \\ ${ }^{a}$ Laboratoire de Physique Atmosphérique et Planétaire (LPAP), Université de Liège, \\ Liège, Belgium. \\ ${ }^{b}$ Laboratoire Atmosphères, Milieux, Observations Spatiales (LATMOS), Université de \\ Versailles Saint-Quentin, Guyancourt, France.
}

\begin{abstract}
Ultraviolet (UV) spectra of the $\delta$ (190-240 nm) and $\gamma(225-270 \mathrm{~nm})$ bands of the nitric oxide (NO) molecule have been measured on the nightside of the atmosphere of Venus with the Spectroscopy for Investigation of Characteristics of the Atmosphere of Venus (SPICAV) instrument on board Venus Express (VEX). Excited NO molecules on the nightside of the planet are created by radiative recombination of $\mathrm{O}\left({ }^{3} \mathrm{P}\right)$ and $\mathrm{N}\left({ }^{4} \mathrm{~S}\right)$ atoms. The atoms are produced by photodissociation of $\mathrm{CO}_{2}$ and $\mathrm{N}_{2}$ molecules on the dayside and then transported on the nightside by the global circulation. We analyse all nightside limb profiles obtained since 2006 and provide a statistical study of the nitric oxide airglow layer and its variability. We also apply a spatial deconvolution and an Abel inversion method to the limb profiles to retrieve and quantify the volume emission rate distribution and its dependence on several factors. We also show that about $10 \%$ of the limb profiles exhibits a
\end{abstract}

\footnotetext{
*Corresponding author

Email address: Arnaud.Stiepen@ulg.ac.be (A.Stiepen)

${ }^{1}$ Allée du 6 Aout, 17, B5C, LPAP, Université de Liège, 4000, Liège, Belgium

${ }^{2} 11$, Boulevard D'Alembert, 78280 Guyancourt, France
} 
secondary peak located above or below the main airglow peak. Furthermore, a one-dimensional chemical-diffusive model is used to simultaneously model the globally averaged $\mathrm{NO}$ and $\mathrm{O}_{2}\left(\mathrm{a}^{1} \Delta_{g}\right)$ airglow vertical distributions using $\mathrm{CO}_{2}$ and $\mathrm{O}$ density profiles rooted in VIRTIS and SPICAV observations. We find that a downward flux of $2 \times 10^{9} \mathrm{~N}\left({ }^{4} \mathrm{~S}\right)$ atoms $\mathrm{cm}^{-2} \mathrm{~s}^{-1}$ and a eddy diffusion coefficient equal to $1 \times 10^{11} / \sqrt{n} \mathrm{~cm}^{-2} \mathrm{~s}^{-1}$, where $\mathrm{n}$ is the total number density, provide the best set of values to parametrize the one-dimensional representation of the complex 3-D dynamical processes.

Keywords: Atmospheres, chemistry, Atmospheres, composition, Atmospheres, dynamics, Atmospheres, structure, Photochemistry, Ultraviolet observations, Venus, Venus, atmosphere 


\section{Introduction}

First spectrographic observations of the delta and gamma bands of nitric oxide in the Venus nightglow were reported by Feldman et al. (1979) with the International Ultraviolet Explorer (IUE) and by Stewart and Barth (1979) with the Pioneer Venus Orbiter (PV-OUVS) ultraviolet spectrometers. The Venus NO ultraviolet spectrum consists of the $\delta(190-240 \mathrm{~nm})$ and $\gamma(225-270$ $\mathrm{nm}$ ) bands. On the dayside of the planet, $\mathrm{N}_{2}$ and $\mathrm{CO}_{2}$ molecules are dissociated by EUV photons and photoelectrons, yielding $\mathrm{O}\left({ }^{3} \mathrm{P}\right)$ and $\mathrm{N}\left({ }^{4} \mathrm{~S}\right)$ atoms that are carried to the nightside by the subsolar to antisolar circulation. The Venus upper atmosphere dynamics has been described as the superposition of two patterns (e.g. Bougher et al. (1997); Bougher et al. (2006); Brecht et al. (2011); Lellouch et al. (1997); Schubert et al. (1980) and Schubert and Covey (2007)). For altitudes below $\sim 70 \mathrm{~km}$, the global wind system is dominated by the retrograde superrotating zonal flow (RSZ) in the direction of the planetary spin and faster than the Venus rotation. Above $\sim 120 \mathrm{~km}$, the motion is dominated by a relatively stable subsolar-to-antisolar flow (SSAS) generated by the inhomogeneous heating of the atmosphere by solar radiation which sets up large pressure gradients. Observations suggest that these two major flow systems superimpose in the transition region (between 70 and 120 $\mathrm{km}$ ), therefore a high variability of these wind components is observed in this region (e.g. Dickinson and Ridley (1977); Schubert et al. (1980); Bougher et al. (2006)). The NO emission is caused by radiative recombination through inverse pre-association of the $\mathrm{O}\left({ }^{3} \mathrm{P}\right)$ and ${ }^{N}\left({ }^{4} \mathrm{~S}\right)$ atoms. This recombination produces NO molecules in the $\left(\mathrm{C}^{2} \Pi\right)$ electronic state that can relax through 


$$
\begin{gathered}
N O\left(C^{2} \Pi\right) \rightarrow N O\left(X^{2} \Pi\right)+\delta \text { bands } \\
N O\left(C^{2} \Pi\right) \rightarrow N O\left(A^{2} \Sigma, v^{\prime}=0\right)+1.22 \mu m \\
N O\left(A^{2} \Sigma, v^{\prime}=0\right) \rightarrow N O\left(X^{2} \Pi\right)+\gamma \text { bands }
\end{gathered}
$$

The total emission rate of the NO $\delta$ and $\gamma$ bands is proportional to the product of the $\mathrm{N}$ and $\mathrm{O}$ densities. Therefore, this airglow bears the signature of the dynamics, temperature and chemical characteristics of the venusian atmosphere. Stewart et al. (1980) showed that the NO airglow exhibits variations from day-to-day both in brightness and morphology. In their daily maps, the brightest spot is located in the range $39^{\circ} \mathrm{S}$ to $60^{\circ} \mathrm{N}$ and 2130 to 0300 LT (Bougher et al. (1990)). They used the PV-OUVS instrument to build a NO nightglow statistical intensity map, showing the presence of a bright spot shifted downward from the antisolar point by approximately 2 hours and about $10^{\circ}$ to $20^{\circ}$ toward the southern hemisphere. While the average hemispheric nightside intensity of the $(0,1) \gamma$ band was 0.48 kiloRayleighs $(\mathrm{kR})$, Bougher et al. (1990) determined the peak to be $1.9 \pm 0.6 \mathrm{kR}$ in the bright spot region. PV-OUVS limb scans from periapsis were used to determine an emission peak altitude of $115 \pm 2 \mathrm{~km}$ (Gérard et al. (1981)). The Spectroscopy for Investigation of Characteristics of the Atmosphere of Venus (SPICAV) instrument (Bertaux et al. (2007)) on board Venus Express (VEX) has provided a large dataset of limb observations of the NO $\delta$ and $\gamma$ bands. An initial analysis based on 201 limb profiles was given by Gérard et al. (2008a). They found that the mean peak altitude was located at $113 \pm 5.8 \mathrm{~km}$ and the average brightness varied from $5 \mathrm{kR}$ at northern mid-latitudes, reaching 
up to $440 \mathrm{kR}$ at lower latitudes. Royer et al. (2010) developed a model to retrieve NO emission from stellar occultation observations by SPICAV. Their results were in agreement with those obtained from other SPICAV science modes (vertical distribution, peak intensity, variability of the emission, location of the bright spot). They successfully identified the emission observed in addition to the stellar spectrum that appears in slitless occultation mode of SPICAV as being a NO emission. They modeled this emission to retrieve the altitude of the peak, its scale height and its brightness. As expressed by relation (2), near-infrared NO nightglow is also produced during the recombination processes. Garcia Munoz et al. (2009) reported the first unambiguous observation of the $\mathrm{NO} \mathrm{C}(0) \rightarrow \mathrm{A}(0)$ band at $1.22 \mu \mathrm{m}$ in the Venus nightglow. The peak of the limb profile of this emission was found between 109 and 112 $\mathrm{km}$, with a maximum of 7.9-63 $\mathrm{kR}$. The characteristics of the NIR and the UV NO emissions are consistent as the Venus atmosphere is optically thin at these altitudes for all three NO emissions ( $\delta$ band, $\gamma$ band and the $1.22 \mu \mathrm{m}$ ). The $\mathrm{O}_{2} 1.27 \mu \mathrm{m}$ IR nightglow was first observed by Connes et al. (1979) using a ground-based Fourier transform spectrometer. Exclusive ground-based (e.g. Crisp et al. (1996); Hueso et al. (2008); Krasnopolsky (2010); Ohtsuki et al. (2005); Ohtsuki et al. (2008) and Bailey et al. (2008)) and space-borne observations from Venus Express have been conducted. The Visible and Infrared Thermal Imaging Spectrometer (VIRTIS) instrument (Drossart et al. (2007); Piccioni et al. (2009)) is composed of two spectrometers, including the VIRTIS-M-IR instrument. It is well adapted to the observation of the $\mathrm{O}_{2}\left(a^{1} \Delta\right) 1.27 \mu \mathrm{m}$ nightglow in both nadir and limb modes. The horizontal distribution of the emission brightness was studied from nadir VIRTIS obser- 
86

87

vations by Gérard et al. (2008b), Piccioni et al. (2009) and Soret et al. (2012). They found the highest intensity near the antisolar point, with maximum values of respectively $3 \mathrm{MR}, 1.2 \mathrm{MR}$ and 1.6 MR (MegaRayleigh) and a mean intensity for the nightside of $1.3 \mathrm{MR}, 0.52 \mathrm{MR}$ and $0.50 \mathrm{MR}$, respectively. Krasnopolsky (2010) observed from the ground a mean nightside intensity value of $0.55 \mathrm{MR}$. From limb observations, the mean peak brightness was found to be $28 \pm 22 \mathrm{MR}$ at an altitude of $96 \pm 2.7 \mathrm{~km}$ (Gérard et al. (2010); Soret et al. (2012)). The reaction scheme for $\mathrm{O}_{2}\left(a^{1} \Delta\right)$ was first proposed by Connes et al. (1979). They suggested that radiative deexcitation of the $\mathrm{O}_{2}\left(a^{1} \Delta\right)$ molecules follows three-body recombination of oxygen atoms in the upper mesosphere. As previously mentioned, the $\mathrm{O}$ atoms are produced on the Venus dayside by photodissociation and electron impact dissociation of $\mathrm{CO}_{2}$ and $\mathrm{CO}$, and transported to the nightside by the SSAS circulation:

$$
\mathrm{O}+\mathrm{O}+\mathrm{CO}_{2} \rightarrow \mathrm{O}_{2}^{*}+\mathrm{CO}_{2}
$$

$$
O_{2}^{*} \rightarrow O+h \nu
$$

$$
\mathrm{O}_{2}^{*}+\mathrm{CO}_{2} \rightarrow \mathrm{O}_{2}+\mathrm{CO}_{2}
$$

In this study, we improve the preliminary analysis by Gérard et al. (2008a), as we consider a larger dataset. The SPICAV limb profiles are deconvolved to take into account the smoothing effect of the finite instrumental field of view.

The deconvolved profiles are then inverted to obtain vertical profiles of the volume emission rate. Finally, we use a one-dimensional model (described in Section 5) with this new extensive dataset to retrieve nightside average densities $\left(\mathrm{O}_{2}^{*}, \mathrm{NO}\right.$ and $\left.\mathrm{N}\right)$, brightness $\left(\mathrm{O}_{2}^{*}\right.$ and $\left.\mathrm{NO}\right), \mathrm{N}$ flux at $130 \mathrm{~km}$, as well as information about the eddy diffusion coefficient. 


\section{Observations}

The European Space Agency Venus Express spacecraft started orbiting Venus in April 2006. It has a 24-hour elliptical orbit with a pericenter located at high northern latitudes and an apocenter $66000 \mathrm{~km}$ from the planet. Several observing modes may be selected, including nadir, star pointing (for stellar occulations) and limb observations (Titov et al. (2006)). The SPICAVUV instrument was thoroughly described in Bertaux et al. (2007). Because of the quasi-polar elliptical orbit, limb measurements are preferentially made while SPICAV observes the northern hemisphere (see Figure 1). In this study, the primary dataset contains 1352 limb sequences. Several criteria have been analysed to determine whether an observation is included in the database:

1. The local time of the full sequence is between 1800 and 0600 LT (i.e. SPICAV observes the nightside of the planet)

2. The instrumental gain must be high enough to provide adequate signalto-noise ratio

3. It must be a grazing limb mode, i.e. the tangent point altitude must pass through a minimum during the observation.

Each observation consists in 5 adjacent spatial bins of the Charge-Coupled Device (CCD) that are read out every second. Each of these spatial bins projects into a different region of the venusian atmosphere, separated by an angle ranging from 1.4 to 22.4 arcmin. These bins collect the signal through two different slits $(500 \mu \mathrm{m}$ and $50 \mu \mathrm{m}$ width) giving two different spectral resolutions (respectively of 12 and $1.5 \mathrm{~nm}$ ). Limb profiles taken through the wide slit were initially rejected in a previous study (Gérard et al. (2008a)) 
in order to visually verify that the emission analysed consists exclusively in the NO $\gamma$ and $\delta$ bands. Since no other emission has been observed in the spectral range (from $118 \mathrm{~nm}$ to $320 \mathrm{~nm}$ ), observations collected with both slit apertures have been processed in this study. Every second, the CCD collects five different UV spectra of the $\delta$ and $\gamma$ bands. Consequently, on the order of 1000 spectra are recorded in each of the 5 bins per observation. In the grazing-limb mode, the tangent point of the center of the field of view of SPICAV describes two phases: one ingress and one egress, as described in Figure 1 by Gérard et al. (2008a). Consequently, each sequence includes five times two limb scans, each one containing 1000 spectra. The dataset used in this study is composed of 98 orbits, corresponding to 173 sequences. Taking into account the presence of 5 spatial bins, this corresponds to 865 individual limb profiles. As the grazing-limb consists in two sequences (ingress and egress), the dataset contains 1730 limb scans and, consequently, about $1,730,000$ spectra that have been analysed. Data processing of the spectra can be summarized in four steps. During step one, non-uniform dark current and offset values are subtracted from each individual raw spectrum. Step two consists of the intensity calibration in kiloRayleighs $(\mathrm{kR})$ based on wellknown hot star spectra observed by SPICAV during the mission. During step two, all empty profiles are rejected, as well as those where an intensity peak cannot be clearly defined. The SPICAV Point Spread Function (PSF) is used during step three to deconvolve the intensity profiles with a RichardsonLucy method (Lucy (1974)). Finally, in step four, the Volume Emission Rate (VER - in photons $\mathrm{cm}^{-3} \mathrm{~s}^{-1}$ ) is determined via the Abel inversion technique briefly discussed by Gérard et al. (2008b) and described more fully here. The 
available observations do not cover the complete nightside of the planet. As pointed out before, due to geometrical constraints, SPICAV can only observe the northern hemisphere in grazing limb mode with sufficient vertical resolution. The coverage of the limb scans here used in terms of local time and northern latitude is represented in Figure 1. One can notice that the majority of the dataset is situated between 0000 and 0200 LT. Figure 2 shows the mean brightness profile of the NO ultraviolet emission on the nightside of Venus. It was obtained by summing all the deconvolved limb profiles processed in this study. This sum is then divided by the number of profiles summed. The mean peak altitude is located at $115.5 \mathrm{~km}$ for a mean peak brightness of $60 \mathrm{kR}$. In figure 2, the intensity profile illustrates an interesting behaviour of sudden changes for altitudes lower than $100 \mathrm{~km}$. This effect is probably due to the absorption and scattering of the UV NO photons by the upper haze layer and will be discussed in section 4. Histograms are used to represent the global distribution of the peak brightness and peak altitudes. The top panel in Figure 3 represents the peak brightness distribution on a logarithmic scale where the brightness appears as a Gaussian-like shape. The mode has a value of $50 \mathrm{kR}$ with a one-sigma standard deviation of $40 \mathrm{kR}$ and $200 \mathrm{kR}$. The altitude distribution shows that most of the occurrences are in the $108-114 \mathrm{~km}$ range. The mode is located at $110 \mathrm{~km}$, that is $5.5 \mathrm{~km}$ below the mean peak altitude of the limb brightness. The distribution also exhibits a quasi-Gaussian shape with a one-sigma standard deviation of $5 \mathrm{~km}$. The difference between the mode of the altitude distribution and the mean profile peak altitude indicates that, statistically, profiles with a large peak intensity tend to have higher peak altitudes. 


\section{Emission peak analysis}

equation (8) may be expressed as:

$$
I=2 \int_{z_{t g}}^{+\infty} \frac{z}{\sqrt{z^{2}-z_{t g}^{2}}} P(z) d z
$$

180 of all local emission elements along the line of sight, i.e.:

$$
I=\int_{-\infty}^{+\infty} P(s) d s
$$
becomes

$$
I=2 \int_{0}^{+\infty} P(s) d s
$$

Changing variable analysing geometric relationship

$$
(z+R)^{2}=s^{2}+\left(z_{t g}+R\right)^{2}
$$
radius. cubic splines whose parameters minimize the following expression:

In the absence of self-absorption, a limb emission observed with an instrument such as SPICAV can be considered as the sum of the contribution

where I is the observed intensity, ds an infinitesimal element of the line of sight and $\mathrm{P}(\mathrm{s})$ is the local emission rate of the $\mathrm{s}^{\text {th }}$ element of the line of sight. If the emission geometry is considered spherically symmetric, expression (7)

where $\mathrm{z}$ is the altitude, $z_{t g}$ is the tangent point altitude, $\mathrm{R}$ is the planetary

Expression (10) is the Abel integral. The search for $\mathrm{P}(\mathrm{z})$ from this expression is the Abel inverse transform. Within the assumption of spherical symmetry of the emission rate, the inverted profile is approximated with 


$$
S=(1-\lambda) \int\left(c A(P(z))-I_{o b s}\right)^{2} d z+\lambda R
$$

In this relation, $\mathrm{A}(\mathrm{P}(\mathrm{z}))$ is the Abel transform of the local emission rate $\mathrm{P}(\mathrm{z})$ and $\lambda$ is a parameter that controls the relative importance of the two terms. The value of $\lambda$ is chosen in order that the data fidelity term (the first term of expression (11)) ends up being equal to the estimated variance of the noise. $\mathrm{I}_{o b s}$ is the recorded limb emission profile and $\mathrm{c}$ is a coefficient present for physical unit compatibility purpose. $\mathrm{R}$ is a regularization function chosen to be:

$$
R=\int\left(\frac{d^{2} P(z)}{d z^{2}}\right)^{2} d z
$$

The acquisition of an inverse smoothed profile is obtained through this regularization function. This inversion technique has been used to characterize the behavior of the volume emission rate. Figure 4 shows the average of all inverted limb profiles used in this study. The scale is logarithmic for a better representation of the wide range of values of the VER. As pointed out before, the peak VER reaches 965 photons $\mathrm{cm}^{-3} \mathrm{~s}^{-1}$. Below $100 \mathrm{~km}$ and above $130 \mathrm{~km}$, the emission becomes vanishingly faint. The difference between the peak altitude of the the mean limb profile and that of the VER is a consequence of the Abel inversion described above. The mean peak altitude of the VER is 115 with a standard deviation of $\pm 7 \mathrm{~km}$. The amplitude of the variability is much larger than the uncertainty in the altitude of the peak emission, which is less than $1 \mathrm{~km}$, as mentioned below.

We estimated the noise propagation through the inversion technique following the method described by Ramsey et al. (1999). For this purpose, a 
representative deconvolved profile with its error bars is represented in figure 5, panel a. This observation was made at $44^{\circ} \mathrm{N}, 01: 00 \mathrm{LT}$ during orbit 324 . We randomly generated 1,000 profiles constructed as follows. To each data point, a random noise is added, chosen to follow a normal distribution whose mean value is equal to the observed intensity and whose standard deviation is equal to the local error bar. Each one of the 1,001 profiles is individually inverted following the inversion method described before. Figure 5 panel b shows the inverted profile and the estimated uncertainty. The black diamonds represent the inversion of the observed limb profile while the grey zone illustrates the one-sigma scatter results for the inversion of the other 1,000 profiles. The uncertainty of the altitude of the peak VER is less than $1 \mathrm{~km}$, the vertical resolution adopted in the inversion procedure. This estimate of the propagation of the noise has been performed on a series of limb profiles with various peak altitudes and intensities. The peak VER uncertainty is a factor $\sim 2$ while the peak deconvolved brightness uncertainty is $\sim 10 \%$.

Figure 6 top panel represents the distribution of the VER peaks derived from the limb profiles. The mean value is $\sim 1000$ photons $\mathrm{cm}^{-3} \mathrm{~s}^{-1}$ and the distribution exhibits a standard deviation from 630 up to $\sim 5000$ photons $\mathrm{cm}^{-3} \mathrm{~s}^{-1}$. The multiplicative factor between two bins is 1.6, which is of the same order of magnitude as the peak VER uncertainty. The bottom panel shows the distribution of the altitudes of the peak VER. It exhibits a mean altitude of $115 \pm 7 \mathrm{~km}$, as indicated in Figure 4 . The very large variability in both the value of the peak VER and its peak altitude is noticeable. The mean peak altitude is $115 \mathrm{~km}$, and the mean peak VER reaches 965 photons $\mathrm{cm}^{-3} \mathrm{~s}^{-1}$. However, several observations show an unexpectable high peak al- 
titude above $125 \mathrm{~km}$. Such large values of the peak altitude are associated with large values of the VER. A slight trend for low peak altitude and weaker peak VER also appears. Further analysis of the peak VER and its altitude as a function of latitude, local time and solar zenith angle is illustrated in Figure 7. A tendency for a decrease of the VER with increasing latitude from the equator to $20^{\circ} \mathrm{N}$ is observed in Figure $7 \mathrm{a}$. VER values drop by a factor $\sim 3$ from $5^{\circ} \mathrm{N}$ to $65^{\circ} \mathrm{N}$. Observations have been made at higher latitudes, but the presence of solar scattered light could not be excluded and these observations have therefore been rejected. The relation between NO airglow intensity and local time has been previously described in the literature (e.g. Stewart et al. (1980) and Bougher et al. (1990)). Figure 7b confirms that highest VER values occur near 0200 LT, in good agreement with the airglow observations by Stewart and Barth (1979) and the statistical map by Stewart et al. (1980). The trend is a decrease of the VER for both larger and smaller values of the local time. Some exceptions have appeared during data processing for both highest (close to 0600 LT) and lowest (close to 1800 LT) local time values. As pointed out before, the presence of a solar UV component made some data unusable. The mean VER peak value at $0200 \mathrm{LT}$ is 1250 photons $\mathrm{cm}^{-3} \mathrm{~s}^{-1}$ dropping to 435 photons $\mathrm{cm}^{-3} \mathrm{~s}^{-1}$ at $0400 \mathrm{LT}$. The variation of the peak altitude as a function of the angular distance from the brightest spot is represented in Figure 7c. The brightness spot for the UV nightglow has been found on average (center of the statistical bright spot) to be shifted from the antisolar point which is in agreement with the dynamics as presented previously (e.g. Dickinson and Ridley (1977) and Schubert et al. (1980)) and past observations (e.g. Stewart et al. (1980) and Bougher 
et al. (1990)). At large values of the Angle from Bright Spot (ABS), peak altitude values must be carefully considered because of the presence of solar straylight near the terminator. For the peak altitude situation, a decrease is found for large (greater than $\sim 50^{\circ}$ ) ABS. If the mean peak altitude of 114.5 $\mathrm{km}$ is consistent for smaller ABSs, data suggest a general decreasing trend for larger ABSs. A search for mean profiles for both low and high ABS values has been undertaken. It has been found that for high ABS values, profiles with a high VER exhibit a peak altitude near $115 \mathrm{~km}$, while profiles with lower VER values show a peak altitude closer to $110 \mathrm{~km}$. We also found a slight decreasing trend of the VER intensities with increasing ABS values, with a noticeable exception for $\sim 60^{\circ}$ ABS.

\section{Multiple peaks}

New features in some vertical profiles have been identified. A secondary peak is found in about $10 \%$ of the analysed limb scans. In $\sim 5 \%$ of the limb scans, a third peak is also observed. The altitude of the second peak is $87 \pm 6 \mathrm{~km}$. The second peak altitude is $26 \pm 5 \mathrm{~km}$ below the main peak altitude in the multiple-peaks limb scans which, in these profiles, is located at $111 \pm 5 \mathrm{~km}$. The mean peak altitude in these profiles is $4 \mathrm{~km}$ below the mean peak altitude within the full database considered, but remains within the boundaries of the standard deviation of the peak altitude. In the cases of the presence of a third peak, its mean altitude is $149 \pm 6 \mathrm{~km}$. This is $39 \pm 12 \mathrm{~km}$ above the mean main peak altitude for these limb scans. The mean main peak altitude in these cases is $110 \pm 7 \mathrm{~km}$. Relative intensities for the multiple peaks have been calculated. On the average, the higher 
peak intensity is $6.8 \pm 3 \%$ of the main peak, while the lower peak intensity is $43 \pm 10 \%$ of the main peak intensity. We also note that the upper peak has never been observed in profiles without a lower peak. When available, $\mathrm{O}_{2}$ $1.27 \mu \mathrm{m}$ limb profiles obtained with VIRTIS have been used for comparison. These $\mathrm{O}_{2}$ profiles are taken while both SPICAV and VIRTIS observed the same region of the Venus atmosphere. Because of the different fields of view of the two instruments, deconvolved profiles from VIRTIS and SPICAV have been used for this comparison. Figure 8 shows an example of a limb profile obtained with the SPICAV instrument during orbit 322 and an $\mathrm{O}_{2}$ profile derived from co-located VIRTIS observations. The standard deviation of the emission is represented by the horizontal error bars. In Figure 8, the $\mathrm{O}_{2}\left(a^{1} \Delta\right)$ intensities (triangles) are divided by a factor $1 \times 10^{6}$ for a consistent scaling with the NO intensities (diamonds). The NO airglow profile peaks at 114 $\mathrm{km}$ and the $\mathrm{O}_{2}$ profile peak altitude is $95 \mathrm{~km}$. An unambiguous second peak in the NO emission is observed at $84 \mathrm{~km}$. Figure 8 shows a third peak emission in the NO airglow vertical profile at an altitude of $143 \mathrm{~km}$. In all profiles analysed, no correlation has been found between the presence of multiple peaks in the $\mathrm{NO}$ and $\mathrm{O}_{2}$ emissions. This is in perfect agreement with Gérard et al. (2009a) and Collet et al. (2010) who both described the lack of correlation between the two emission peaks.

\subsection{Lower peak}

Based on SPICAV/SOIR solar occultations, Wilquet et al. (2009) concluded that two types of particles coexist in the high altitude haze layer from 70 to over $100 \mathrm{~km}$. The first type has a radius comprised between 0.1 and $0.3 \mu \mathrm{m}$ and the other one has a radius between 0.4 and $1 \mu \mathrm{m}$. The 
smallest particles exhibit signatures of UV absorption. They also observed a great temporal variability of the upper haze layer opacity and of the aerosol densities in the Venus mesosphere. We suggest that the lower altitude NO emission peak is linked to the presence of this upper haze layer. As photons are emitted mainly from around the peak altitude (i.e. around $115 \mathrm{~km}$ ), a fraction is backscattered within the haze layer. Hence, at the haze layer altitudes, the observed emission is equal to the local NO emission plus the haze-scattered NO emission. This is in agreement with the spectral composition of the emission at lower altitudes that is identical to the NO spectrum presented in Gérard et al. (2008a). Wilquet et al. (2009) show in their Figure 6 the vertical profiles of the $\beta$ extinction coefficient obtained from data acquired with SPICAV-UV. One can notice the large values for the $\beta$ coefficient at altitudes $\sim 85 \mathrm{~km}$. This is in good agreement with the altitudes of the second peak emission in the $\mathrm{NO}$ vertical profiles.

\subsection{Upper peak}

The higher altitude peak emission, near $149 \mathrm{~km}$, is possibly caused by the presence of gravity waves. Kasprzak et al. (1988) and Kasprzak et al. (1993) found wave-like perturbations in the density profiles of $\mathrm{He}, \mathrm{N}, \mathrm{O}, \mathrm{N}_{2}$ and, in particular, $\mathrm{CO}_{2}$ using the Pioneer Venus Orbiter Mass Spectrometer in an altitude range coherent with our observations altitude range. These observations were taken in the 0.5-4.5 LT region of the planet. Perturbations in the structure of the Venus mesosphere have been identified by Garcia et al. (2009). They were observed in $\mathrm{CO}_{2}$ non-LTE emissions in the altitude range $110-140 \mathrm{~km}$. The amplitude of the perturbation was found to be $0.5 \%$ of the background signal. Gravity waves exhibit a horizontal wavelength from 
90 to $400 \mathrm{~km}$ and horizontal velocities of $70 \mathrm{~ms}^{-1}$ westward and $30 \mathrm{~ms}^{-1}$ northward. Garcia et al. (2009) assumed that they are generated by the polar vortex. The NO airglow upper peak may be produced by a secondary emission layer located near $149 \mathrm{~km}$ stemming from local enhancements of the $\mathrm{O}$ density above $110 \mathrm{~km}$, the altitude of the $\mathrm{O}$ density peak in normal conditions. The vertical wavelength of the gravity wave is thought to be $\sim 15$ $\mathrm{km}$, corresponding to the distance between the main emission peak and the upper NO airglow emission peak.

\section{One-Dimensional Modeling}

The transport of $\mathrm{O}$ and $\mathrm{N}$ atoms from the day to the nightside and the subsequent downward motion on the nightside is a complex three-dimensional problem requiring a solution of primitive conservation equations (e.g. Bougher et al. (1990); Bougher and Borucki (1994); Bougher et al. (2006) and Brecht et al. (2011)). A simplified approach consists in solving a one-dimensional set of coupled continuity equations for $\mathrm{N}\left({ }^{4} \mathrm{~S}\right), \mathrm{NO}, \mathrm{O}\left({ }^{3} \mathrm{P}\right)$ and $\mathrm{O}_{2}\left({ }^{1} \Delta\right)$. In this formalism, the topside boundary condition is a downward flux value while the bottomside condition is a zero flux condition. We briefly describe the one-dimensional chemical-diffusive model we use to quantitatively examine the parameters controlling the altitude and the intensity of the NO emission. This model was described by Cox et al. (2008) to analyse the NO nightglow on Mars. It was adapted by Gérard et al. (2008a) to the case of the

Venus atmosphere. The continuity equation for a minor constituent $\mathrm{i}$ in the thermosphere may be written:

$$
\frac{\partial n_{i}}{\partial t}=-\frac{\partial \phi_{i}}{\partial z}+P_{i}-L_{i}-\frac{\partial\left(n_{i} w\right)}{\partial z}
$$


with $n_{i}$ the density of the $i^{\text {th }}$ constituent, variable in time $\mathrm{t}, \mathrm{z}$ is the altitude considered positive upward, $\mathrm{P}_{i}$ its production rate, $\mathrm{L}_{i}$ its loss rate and $\mathrm{w}$ the vertical component of the velocity considered positive upward. The use of a vertical upward velocity component is meaningless to describe the globally averaged profile of the constituents. The model is here used to reproduce a mean observation that represents the global averaged nightglow emissions. The SSAS circulation at this altitude range provides a downward flux. However, a vertical upward velocity may be introduced to reproduce local observations. The vertical diffusive flux $\phi_{i}$ of the i minor constituent is given by:

$$
\phi_{i}=-\left(D_{i}+K\right)\left(\frac{\partial n_{i}}{\partial z}+\frac{n_{i}}{T} \frac{\partial T}{\partial z}\right)-\left(\frac{D_{i}}{H_{i}}+\frac{K}{H}\right) n_{i}
$$

with $\mathrm{D}_{i}$ the molecular diffusion constituent, $\mathrm{K}$ the vertical eddy diffusion coefficient, $\mathrm{H}_{i}$ the scale height of constituent i, $\mathrm{H}$ the atmospheric scale height, T the neutral gas temperature. Following von Zahn et al. (1979), the vertical variation of the eddy diffusion coefficient $\mathrm{K}$ is expressed by:

$$
K(z)=\frac{A}{\sqrt{n(z)}} \mathrm{cm}^{2} \mathrm{~s}^{-1}
$$

with $\mathrm{A}$ a parameter independent of the altitude.

Table 1 presents the rate coefficients of the chemical reactions considered in the model. These are:

$$
N+O \stackrel{k_{1}}{\rightarrow} \mathrm{NO}+h \nu_{U V}
$$

$$
\mathrm{N}+\mathrm{O}+\mathrm{CO}_{2} \stackrel{k_{2}}{\rightarrow} \mathrm{NO}+\mathrm{CO}_{2}
$$

$$
\mathrm{N}+\mathrm{NO} \stackrel{k_{3}}{\rightarrow} \mathrm{N}_{2}+\mathrm{O}
$$




$$
\begin{gathered}
O+O+\mathrm{CO}_{2} \stackrel{k_{4}}{\rightarrow} \mathrm{O}_{2}^{*}+\mathrm{CO}_{2} \\
\mathrm{O}_{2}\left({ }^{1} \Delta_{g}\right)+\mathrm{CO}_{2} \stackrel{k_{5}}{\rightarrow} \mathrm{O}_{2}+C O_{2}^{*} \\
\mathrm{O}_{2}\left({ }^{1} \Delta_{g}\right) \stackrel{k_{6}}{\rightarrow} \mathrm{O}_{2}+h \nu_{I R}
\end{gathered}
$$

The $\mathrm{CO}_{2}$ density and temperature profiles from 80 to $130 \mathrm{~km}$ are taken from Soret et al. (2012) figure 5, Brecht et al. (2012) figure 2 and Hedin et al. (1983), Krasnopolsky (2011) respectively. Soret et al. (2012) reported results from stellar occultation observations performed with SPICAV-UV on the Venus nightside. The mean $\mathrm{CO}_{2}$ vertical distribution for the Venus nightside has been obtained by averaging the individual profiles derived from the SPICAV occultations for all night local times and latitudes, as described in Soret et al. (2012), section 3.2. The amount of $\mathrm{CO}_{2}$ along a line of sight is inferred from the variation of the transmission of the brightness of a UV star between 120 and $200 \mathrm{~nm}$ as the instrument points within the atmosphere of Venus. An inversion technique uses the Beer-Lambert's law to retrieve opacity. The number of $\mathrm{CO}_{2}$ molecules is then retrieved with an inversion procedure using a Levenberg-Marquardt fitting technique. Similar, the oxygen profile was derived from the $\mathrm{O}$ map based on VIRTIS observations of the $\mathrm{O}_{2}\left(\mathrm{a}^{1} \Delta\right)$ airglow distribution completed with the $\mathrm{CO}_{2}$ distribution derived from SPICAV data. Our model is therefore applied to retrieve nitrogen downward flux at the upper altitude boundary at $130 \mathrm{~km}$ and the strength of eddy mixing adequate to a one-dimensional approach. Nitrogen atoms recombine with oxygen atoms to produce the NO airglow emission as described by reaction 16 . Equation 13 is solved between $80 \mathrm{~km}$ and $130 \mathrm{~km}$ with the finite volume method on a constant altitude grid. At the upper boundary, 
the $\mathrm{N}\left({ }^{4} \mathrm{~S}\right)$ flux is a free parameter determined by fitting the modeled limb profile to the observations, whereas the $\mathrm{O}\left({ }^{3} \mathrm{P}\right)$ density profile is considered as observationally known and not allowed to vary. The model finally integrates the $\mathrm{k}[\mathrm{O}][\mathrm{N}]$ product along the line of sight to simulate the limb profile of the NO emission. As in previous studies (Gérard et al. (2008a)), our representation takes into account a vertical transport term that is the sum of molecular and eddy diffusions. Turbulent transport is parametrized by the $\mathrm{K}$ coefficient, and, following relation (15), is controlled by the A parameter. We first analyze the impact of using a fixed or free $\mathrm{O}$ density profile. With a free $\mathrm{O}$ density profile and boundary conditions taken from Gérard et al. (2008a), the best NO airglow fit was obtained with $\mathrm{A}=4 \times 10^{12}$, $\phi_{o}=1 \times 10^{12} \mathrm{~cm}^{-2} \mathrm{~s}^{-1}$ and $\phi_{n}=2.3 \times 10^{9} \mathrm{~cm}^{-2} \mathrm{~s}^{-1}$. It yields a NO maximum intensity for a tangent altitude of $115 \mathrm{~km}$ and a peak intensity of 61 $\mathrm{kR}$. These parameters provide an $\mathrm{O}_{2}$ airglow peak altitude of $102 \mathrm{~km}$ and an intensity of $52 \mathrm{MR}$. This intensity is too bright and peaks $6 \mathrm{~km}$ above those derived from VIRTIS observations (Gérard et al. (2009b); Soret et al. (2012)). The distance between the two peaks of $\mathrm{NO}$ and $\mathrm{O}_{2}$ emissions was discussed in Collet et al. (2010) and Brecht et al. (2011). They both modeled a distance smaller than determined from observations. We then analysed the impact of the A parameter on both $\mathrm{NO}$ and $\mathrm{O}_{2}$ vertical profiles, with a mean oxygen density profile taken from Soret et al. (2010). Figure 9 illustrates some of the results. Diamonds represent the NO airglow profiles for $\mathrm{A}=1$ $\times 10^{15}$ (red) to $\mathrm{A}=1 \times 10^{10}$ (dark blue). One notices that both altitude and peak intensity vary, with a maximum peak altitude of $113 \mathrm{~km}$. The $\mathrm{O}_{2}$ $\left(a^{1} \Delta\right)$ emission (triangles) is less A-dependent in these simulations than the 
NO UV emission. This stems from the fact that the $\mathrm{O}$ density profile is fixed to its experimentally determined altitude. For A values less than $10^{15}$, the six different curves of the $\mathrm{O}_{2}$ emission are superimposed. For A equal to or larger than $10^{15}$ (red curve), turbulent mixing is strong enough to carry downward excited $\mathrm{O}_{2}$ molecules where they are partly quenched by collisions with $\mathrm{CO}_{2}$. In the same way, $\mathrm{NO}$ profiles are superimposed for A values equal to or smaller than $10^{12}$. Figure 9 also exhibits a drop in the NO intensity for high values of A: as the NO emission layer moves downward, reaction (17) which does not produce NO $\gamma$ or $\delta$ photons, takes over reaction (16).

Finally, we fitted the mean NO emission profile, as presented in Section 2. We found that, with a fixed vertical profile of $\mathrm{O}$ density derived from VIRTIS $\mathrm{O}_{2}\left(a^{1} \Delta\right)$ observations, the best fit parameters are $\phi_{N}=2.1 \times 10^{9}$ $\mathrm{cm}^{-2} \mathrm{~s}^{-1}$ and $\mathrm{A}=1 \times 10^{11}$. Gérard et al. (1988), Bougher et al. (1990) and Brecht et al. (2011) found a mean nightside N atom downward flux of $2.1 \times 10^{9}, 1 \times 10^{9}$ and $2 \times 10^{9} \mathrm{~cm}^{-2} \mathrm{~s}^{-1}$ respectively. In his nightside photochemical model, Krasnopolsky (2010) found a nightside $\Phi_{N}$ equal to $1.2 \times 10^{9}$. These corresponding to a global mean dayside $\mathrm{N}$ production values of $1.3 \times 10^{10}, 1 \times 10^{9}$ and $1.6 \times 10^{10}$. All of these values are consistent with our best fit $\mathrm{N}$ flux. We also found that, in a one-dimensional approach, the A parameter is the only parameter controlling both the NO peak altitude and peak intensity, while the downward nitrogen flux only acts on the peak intensity. However, the model does not correctly predict a peak altitude of $115.5 \mathrm{~km}$. An upward local wind in relation (13) would permit to simulate higher NO emission peak altitude, but this term would be meaningless in a global scale model. However, with $\phi_{N}=2.1 \times 10^{9} \mathrm{~cm}^{-2} \mathrm{~s}^{-1}$ and $\mathrm{A}=1 \times 10^{11}$, 
as the model could reproduce $\mathrm{O}_{2}$ airglow peak altitude, the distance between the two airglow layers is almost in agreement with the observations and both $\mathrm{O}_{2}$ and NO peak intensities fit the observations. The model density profiles for atomic nitrogen, nitric oxide and $\mathrm{O}_{2}\left(a^{1} \Delta\right)$ as well as the $\mathrm{O}$ density profile from Soret et al. (2012) are shown in Figure 10. We stress that, in Figure 2, roughly a fourth of the observations exhibit a peak altitude higher than 113 $\mathrm{km}$. Our one-dimensional model could reproduce $75 \%$ of the observations peak altitudes. The decrease of peak altitude with larger values of ABS in Figure 7 may be reproduced by the model. The peak altitude in these observations drops to $108 \mathrm{~km}$ at an angle of $75^{\circ}$ from brightest spot. This corresponds to a A value of $1 \times 10^{12}$ and a nitrogen flux of $2.5 \times 10^{9} \mathrm{~cm}^{-2} \mathrm{~s}^{-1}$.

\section{Conclusions}

We have greatly increased the statistical basis of $\mathrm{NO} \gamma$ and $\delta$ airglow limb profiles and confirmed the general trends previously described using a more restricted database. The maximum emission rate is found at $115.5 \pm 7 \mathrm{~km}$ with a mean brightness of $60 \mathrm{kR}$. We present the first study of the volume emission rate of the NO emission following deconvolution and Abel inversion of the limb profiles. The peak volume emission rate and altitude are analysed in regard with factors such as latitude, angle from the brightest spot of the NO nightglow and local time. We observe a drop of the peak volume emission rate with increasing northern latitudes, a decrease of the peak volume emission rate and peak altitude with increasing angle from the center of the statistical bright spot and an increase of the peak volume emission rate around $0200 \mathrm{LT}$. We also find a slight trend for profiles with higher peak 
volume emission rates to correspond to higher peak altitudes. A second and a third peak are observed in respectively $\sim 10 \%$ and $\sim 5 \%$ of the limb scans. The second peak mean altitude is $87 \pm 6 \mathrm{~km}$ with a brightness corresponding to $43 \pm 10 \%$ of the main peak brightness. It is believed to be caused by scattering of the photons for emission within the haze layer. The third peak mean altitude is $149 \pm 6 \mathrm{~km}$. It has a relative brightness of $6.8 \pm 3 \%$ of the mean main peak brightness. This peak is likely caused by gravity waves with vertical wavelength of $15 \pm 3 \mathrm{~km}$. A one-dimensional chemical-diffusive model has been used to fit the main features of these and $\mathrm{O}_{2}\left({ }^{1} \Delta\right)$ observations. The use of $\mathrm{CO}_{2}$ and $\mathrm{O}$ density profiles derived from Venus Express instruments SPICAV and VIRTIS makes it possible to reproduce the observed distance between the $\mathrm{O}_{2}$ and $\mathrm{NO}$ emissions. With a $\mathrm{K}$ coefficient of $1 \times 10^{11} / \sqrt{n}$ $\mathrm{cm}^{-2} \mathrm{~s}^{-1}$ and a downward $\mathrm{N}$ flux of $2 \times 10^{9} \mathrm{~cm}^{-2} \mathrm{~s}^{-1}$ at $130 \mathrm{~km}$, the model correctly predicts both the $\mathrm{NO}$ and $\mathrm{O}_{2}$ mean peak altitude and intensity.

\section{Acknowledgments}

The authors thank the SPICAV and the Venus Express teams for the excellent quality of their work. This research was supported by the PRODEX program of the European Space Agency (ESA) managed with the help of the Belgian Space Policy Office (BELSPO). The construction of the SPICAV instrument was funded by CNRS, CNES and ESA/PRODEX. 


\section{References}

Bailey, J., Meadows, V.S., Chamberlain, S., Crisp, D., 2008. The temperature of the Venus mesosphere from $\mathrm{O}_{2}\left(\mathrm{a}^{1} \Delta \mathrm{g}\right)$ airglow observations. Icarus 197, 247-259.

Bertaux, J.L. et al, 2007. SPICAV on Venus Express: Three spectrometers to study the global structure and composition of the Venus atmosphere. Planet. Space Sci. 55, 1673-1700.

Bougher, S.W., Gérard, J.C., Stewart, A.I.F., Fessen, C.G., 1990. The Venus nitric oxide night airglow - Model calculations based on the Venus Thermospheric General Circulation Model. J. Geophys. Res. 95, 6271-6284.

Bougher, S.W., Borucki, W.J., 1994. Venus O2 visible and IR nightglow: Implications for lower thermosphere dynamics and chemistry. J. Geophys. Res. 99, 3759-3776.

Bougher, S.W., Hunten, D.M., Phillips, R.J. (Eds.), 1997. Venus II.

Bougher, S.W., Rafkin, S., Drossart, P., 2006. Dynamics of the Venus upper atmosphere: Outstanding problems and new constraints expected from Venus Express. Planet. Space Sci. 54, 1371-1380.

Brecht, A.S., Bougher, S.W., Gérard, J.C., Parkinson, C.D., Rafkin, S., Foster, B., 2011. Understanding the variability of nightside temperatures, NO UV and $\mathrm{O}_{2}$ IR nightglow emissions in the Venus upper atmosphere. J. Geophys. Res. 116, 8004. 
Brecht, A.S., Bougher, S.W., Gérard, J.C., Soret, L., 2012. Atomic oxygen distributions in the Venus thermosphere: Comparisons between Venus Express observations and global model simulations. Icarus 217, 759-766.

Campbell, I.M., Thrush, B.A., 1966. Behaviour of carbon dioxide and nitrous oxide in active nitrogen. Trans. Faraday Soc. 62, 3366-3374.

Collet, A., Cox, C., Gérard, J.C., 2010. Two-dimensional time-dependent model of the transport of minor species in the Venus night side upper atmosphere. Planet. Space Sci. 58, 1857-1867.

Connes, P., Noxon, J.F., Traub, W.A., Carleton, N.P., 1979. $\mathrm{O}_{2}\left({ }^{1} \Delta\right)$ emission in the day and night airglow of Venus. Astrophys. J. 233, L29-L32.

Cox, C., Saglam, A., Gérard, J.C., Bertaux, J.L., González-Galindo, F., Leblanc, F., Reberac, A., 2008. Distribution of the ultraviolet nitric oxide Martian night airglow: Observations from Mars Express and comparisons with a one-dimensional model. J. Geophys. Res. 113, E08012.

Crisp, D., Meadows, V.S., Bézard, B., de Bergh, C., Maillard, J.P., Mills, F.P., 1996. Ground-based near-infrared observations of the Venus nightside: 1.27- $\mu \mathrm{m} \mathrm{O}_{2}\left(\mathrm{a} \Delta_{g}\right)$ airglow from the upper atmosphere. J. Geophys. Res. 101, 4577-4594.

Dalgarno, A., Babb, J.F., Sun, Y., 1992. Radiative association in planetary atmospheres. Planet. Space Sci. 40, 243-246.

Dickinson, R.E., Ridley, E.C., 1977. Venus mesosphere and thermosphere temperature structure. II - Day-night variations. icarus 30, 163-178. 
Drossart, P. et al, 2007. A dynamic upper atmosphere of Venus as revealed by VIRTIS on Venus Express. Nature 450, 641-645.

Feldman, P.D., Moos, H.W., Clarke, J.T., Lane, A.L., 1979. Identification of the UV nightglow from Venus. Nature 279, 221.

Fox, J.L., 1994. Rate coefficient for the reaction N + NO. J. Geophys. Res. $99,6273-6276$.

Garcia, R.F., Drossart, P., Piccioni, G., López-Valverde, M., Occhipinti, G., 2009. Gravity waves in the upper atmosphere of Venus revealed by $\mathrm{CO}_{2}$ nonlocal thermodynamic equilibrium emissions. Journal of Geophysical Research (Planets) 114, 0.

Garcia Munoz, A., Mills, F., Piccioni, G., Drossart, P., 2009. The nearinfrared nitric oxide nightglow in the upper atmosphere of Venus. PNAS $106,985-988$.

Gérard, J.C., Stewart, A.I.F., Bougher, S.W., 1981. The altitude distribution of the Venus ultraviolet nightglow and implications on vertical transport. Geophys. Res. Lett. 8, 633-636.

Gérard, J.C., Deneye, E.J., Lerho, M., 1988. Sources and distribution of odd nitrogen in the Venus daytime thermosphere. Icarus 75, 171-184.

Gérard, J.C., Cox, C., Saglam, A., Bertaux, J.L., Villard, E., Nehmé, C., 2008a. Limb observations of the ultraviolet nitric oxide nightglow with SPICAV on board Venus Express. J. Geophys. Res. 113, E00B03. 
Gérard, J.C. et al, 2008b. Distribution of the $\mathrm{O}_{2}$ infrared nightglow observed with VIRTIS on board Venus Express. Geophys. Res. Lett. 350, 2207.

Gérard, J.C., Cox, C., Soret, L., Saglam, A., Piccioni, G., Bertaux, J.L., Drossart, P., 2009a. Concurrent observations of the ultraviolet nitric oxide and infrared $\mathrm{O}_{2}$ nightglow emissions with Venus Express. J. Geophys. Res. 114.

Gérard, J.C., Saglam, A., Piccioni, G., Drossart, P., Montmessin, F., Bertaux, J.L., 2009b. Atomic oxygen distribution in the Venus mesosphere from observations of $\mathrm{O}_{2}$ infrared airglow by VIRTIS-Venus Express. Icarus 199, 264-272.

Gérard, J.C., Soret, L., Saglam, A., Piccioni, G., Drossart, P., 2010. The distributions of the $\mathrm{OH}$ Meinel and $\mathrm{O}_{2}\left(\mathrm{a}^{1} \Delta-\mathrm{X}^{3} \Sigma\right)$ nightglow emissions in the Venus mesosphere based on VIRTIS observations. Advances in Space Research 45, 1268-1275.

Hedin, A.E.,Niemann, H.B.,Kasprzak, W.T.,Seiff, A., 1983. Global empirical model of the Venus thermosphere. J. Geophys. Res. 88, 73-83.

Hueso, R. et al, 2008. Morphology and dynamics of Venus oxygen airglow from Venus Express/Visible and Infrared Thermal Imaging Spectrometer observations. J. Geophys. Res. 113, 0.

Kasprzak, W.T., Hedin, A.E., Mayr, H.G., Niemann, H.B., 1988. Wavelike perturbations observed in the neutral thermosphere of Venus. J. Geophys. Res. 93, 11237-11245. 
Kasprzak, W.T., Niemann, H.B., Hedin, A.E., Bougher, S.W., 1993. Wavelike perturbations observed at low altitudes by the Pioneer Venus Orbiter Neutral Mass Spectrometer during orbiter entry. Geophys. Res. Lett. 20, $2755-2758$

Krasnopolsky, V.A., 2010. Venus night airglow: Ground-based detection of $\mathrm{OH}$, observations of $\mathrm{O}_{2}$ emissions, and photochemical model. Icarus 207, $17-27$.

Krasnopolsky, V.A., 2011. A Photochemical Model for the Venus Atmosphere at 47-112 km. AGU Fall Meeting Abstracts, G6.

Lellouch, E., Clancy, T., Crisp, D., Kliore, A.J., Titov, D., Bougher, S.W., 1997. Monitoring of Mesospheric Structure and Dynamics, in: Bougher, S.W., Hunten, D.M., Phillips, R.J. (Eds.), Venus II: Geology, Geophysics, Atmosphere, and Solar Wind Environment, p. 295.

Lucy, L.B., 1974. An iterative technique for the rectification of observed distributions. Astronomical Journal 79, 745.

Miller, H., McCord, J., Choy, J., Hager, G., 2001. Measurement of the radiative lifetime of $\mathrm{O}_{2}\left(\mathrm{a}^{1} \Delta_{g}\right)$ using cavity ring down spectroscopy. Journal of Quantitative Spectroscopy and Radiative Transfer 69, 305 - 325.

Ohtsuki, S., Iwagami, N., Sagawa, H., Kasaba, Y., Ueno, M., Imamura, T., 2005. Ground-based observation of the Venus 1.27-micron $\mathrm{O}_{2}$ airglow. Advances in Space Research 36, 2038 - 2042.

Ohtsuki, S., Iwagami, N., Sagawa, H., Ueno, M., Kasaba, Y., Imamura, T., Nishihara, E., 2008. Imaging spectroscopy of the venus 1.27-micron $\mathrm{O}_{2}$ 
airglow with ground-based telescopes. Advances in Space Research 41, $1375-1380$.

Piccioni, G. et al, 2009. Near-IR oxygen nightglow observed by VIRTIS in the Venus upper atmosphere. J. Geophys. Res. 114, 0.

Ramsey, A.T., Diesso, M. , 1999. Abel inversions: error propagation and inversion reliability. Rev. Sci. Instrum. 70.

Royer, E., Montmessin, F., Bertaux, J.L., 2010. NO emissions as observed by SPICAV during stellar occultations. Planet. Space Sci. 58, 1314-1326.

Sander, S. P. et al, 2006. Chemical kinetics and photochemical data for use in Atmospheric Studies Evaluation Number 15. Jet Propulsion Laboratory Publication 06-2.

Schubert, G. et al, 1980. Structure and circulation of the Venus atmosphere. J. Geophys. Res. 85, 8007-8025.

Schubert, G., Covey, C.C., 2007. Venus Atmosphere Dynamics Workshop, in: Planetary Atmospheres, pp. 105-106.

Smith, G.P., Robertson, R., 2008. Temperature dependence of oxygen atom recombination in nitrogen after ozone photolysis. Chemical Physics Letters $458,6-10$.

Soret, L., Gérard, J.C., Piccioni, G., Drossart, P., 2010. Venus OH nightglow distribution based on VIRTIS limb observations from Venus Express. Geophys. Res. Lett. 370, L06805. 
Soret, L., Gérard, J.C., Montmessin, F., Piccioni, G., Drossart, P., Bertaux, J.L., 2012. Atomic oxygen on the Venus nightside: Global distribution deduced from airglow mapping. Icarus 217, 849-855.

Stewart, A.I., Barth, C.A., 1979. Ultraviolet night airglow of Venus. Science $205,59-62$.

Stewart, A.I.F., Gérard, J.C., Rusch, D.W., Bougher, S.W., 1980. Morphology of the Venus ultraviolet night airglow. J. Geophys. Res. 85, 7861-7870.

Titov, D.V. et al, 2006. Venus Express science planning. Planet. Space Sci. 54, 1279-1297.

von Zahn, U., Fricke, K.H., Hoffmann, H.J., Pelka, K., 1979. Venus - Eddy coefficients in the thermosphere and the inferred helium content of the lower atmosphere. Geophys. Res. Lett. 6, 337-340.

Wilquet, V. et al, 2009. Preliminary characterization of the upper haze by SPICAV/SOIR solar occultation in UV to mid-IR onboard Venus Express. J. Geophys. Res. 114, 0. 
Table 1: Rate coefficients of chemical reactions. $\dagger \equiv$ determined from airglow observations and models; $\ddagger \equiv$ experimentally determined.

\begin{tabular}{|c|c|c|}
\hline Reaction & Rate & Reference \\
\hline$N+O \stackrel{k_{1}}{\rightarrow} N O+h \nu_{U V}$ & $k_{1}=1.92 \times 10^{-17} \times(300 / T)^{1 / 2} \times\left(1-0.57 / T^{1 / 2}\right) \mathrm{cm}^{3} \mathrm{~s}^{-1}$ & Dalgarno et al. (1992) $\dagger$ \\
\hline $\mathrm{N}+\mathrm{O}+\mathrm{CO}_{2} \stackrel{k_{2}}{\rightarrow} \mathrm{NO}+\mathrm{CO}_{2}$ & $k_{2}=2 \times 10^{-32} \times(300 / T)^{1 / 2} \mathrm{~cm}^{6} \mathrm{~s}^{-1}$ & Campbell and Thrush (1966) \\
\hline$N+N O \stackrel{k_{3}}{\rightarrow} N_{2}+O$ & $k_{3}=2.5 \times 10^{-10} \times(T / 300)^{1 / 2} \times \exp (-600 / T) \mathrm{cm}^{3} \mathrm{~s}^{-1}$ & Fox $(1994) \dagger$ \\
\hline $\mathrm{O}+\mathrm{O}+\mathrm{CO}_{2} \stackrel{k_{4}}{\rightarrow} \mathrm{O}_{2}^{*}+\mathrm{CO}_{2}$ & $k_{4}=2.8 \times 10^{-32} \mathrm{~cm}^{6} \mathrm{~s}^{-1}$ & Smith and Robertson $(2008) \ddagger$ \\
\hline $\mathrm{O}_{2}\left({ }^{1} \Delta_{g}\right)+\mathrm{CO}_{2} \stackrel{k_{5}}{\rightarrow} \mathrm{O}_{2}+\mathrm{CO}_{2}^{*}$ & $k_{5}=2 \times 10^{-20} \mathrm{~cm}^{3} \mathrm{~s}^{-1}$ & Sander et al. (2006) \\
\hline$O_{2}\left({ }^{1} \Delta_{g}\right) \stackrel{k_{6}}{\rightarrow} O_{2}+h \nu_{I R}$ & $k_{6}=2.19 \times 10^{-4} \mathrm{~s}^{-1}$ & Miller et al. $(2001) \ddagger$ \\
\hline
\end{tabular}




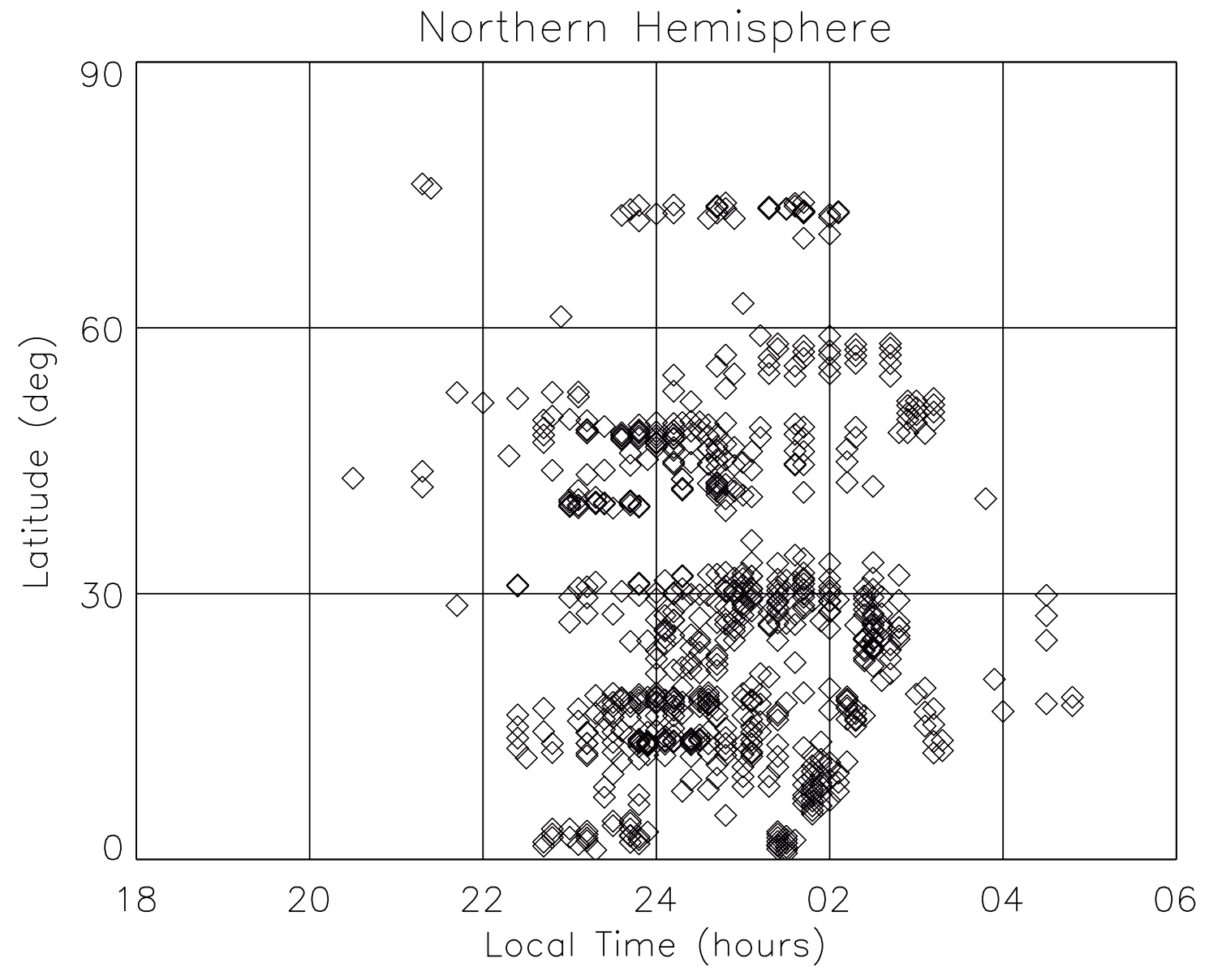

Figure 1: Northern hemisphere coverage of the limb profiles obtained with the SPICAV instrument on Venus Express used in this study in terms of Latitude and Local Time. 


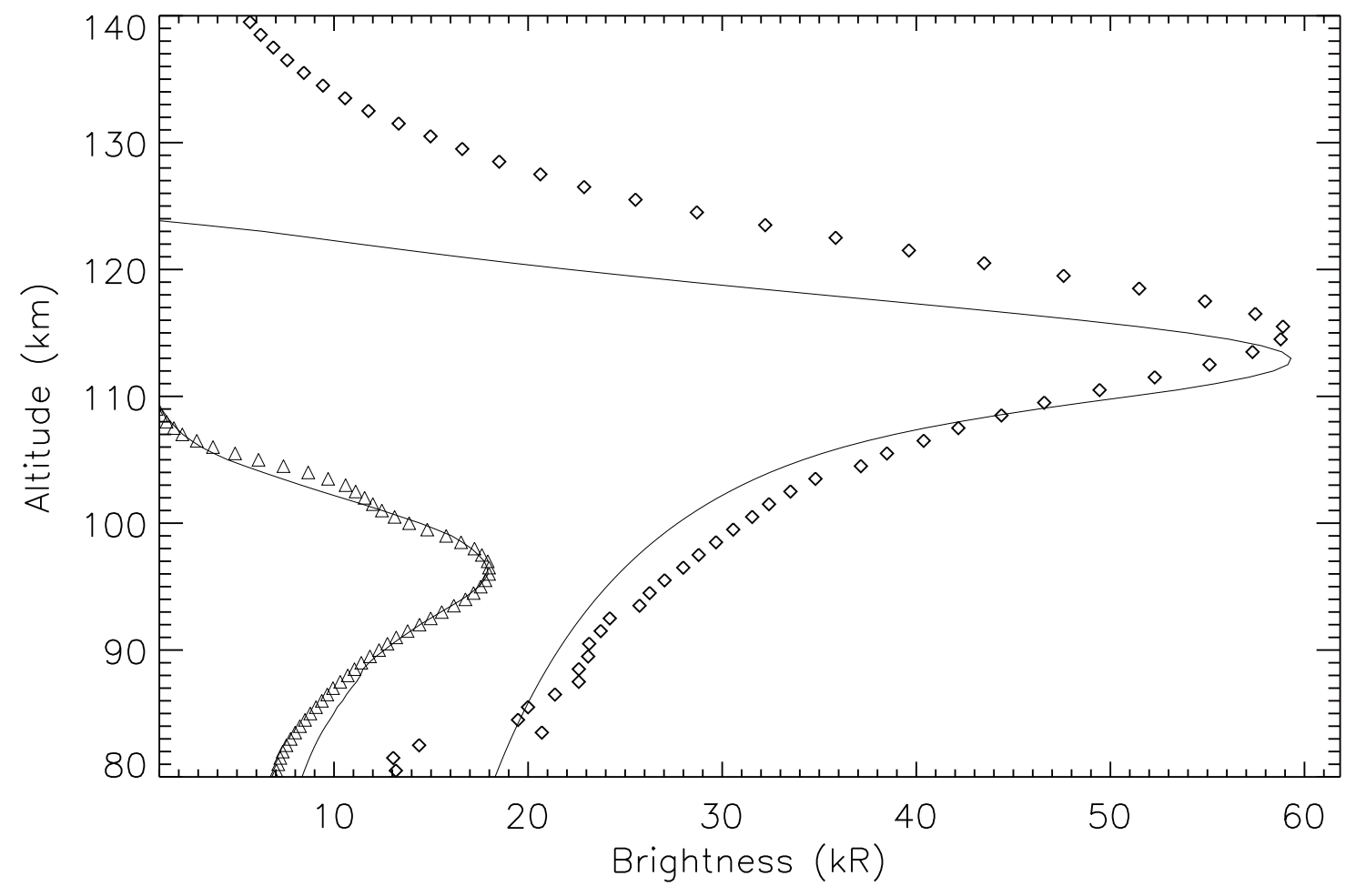

Figure 2: Diamonds: mean brightness profile of the nitric oxide ultraviolet emission. This profile is obtained by summing up all limb observations used in this study. The upper solid line represents the modeled mean brightness profile. Triangles show a representative brightness profile of the $\mathrm{O}_{2} 1.27 \mu \mathrm{m}$ emission, divided by a factor 1000. The lower solid line represents the modeled $\mathrm{O}_{2}$ brightness profile also scaled by a factor 1000 . 

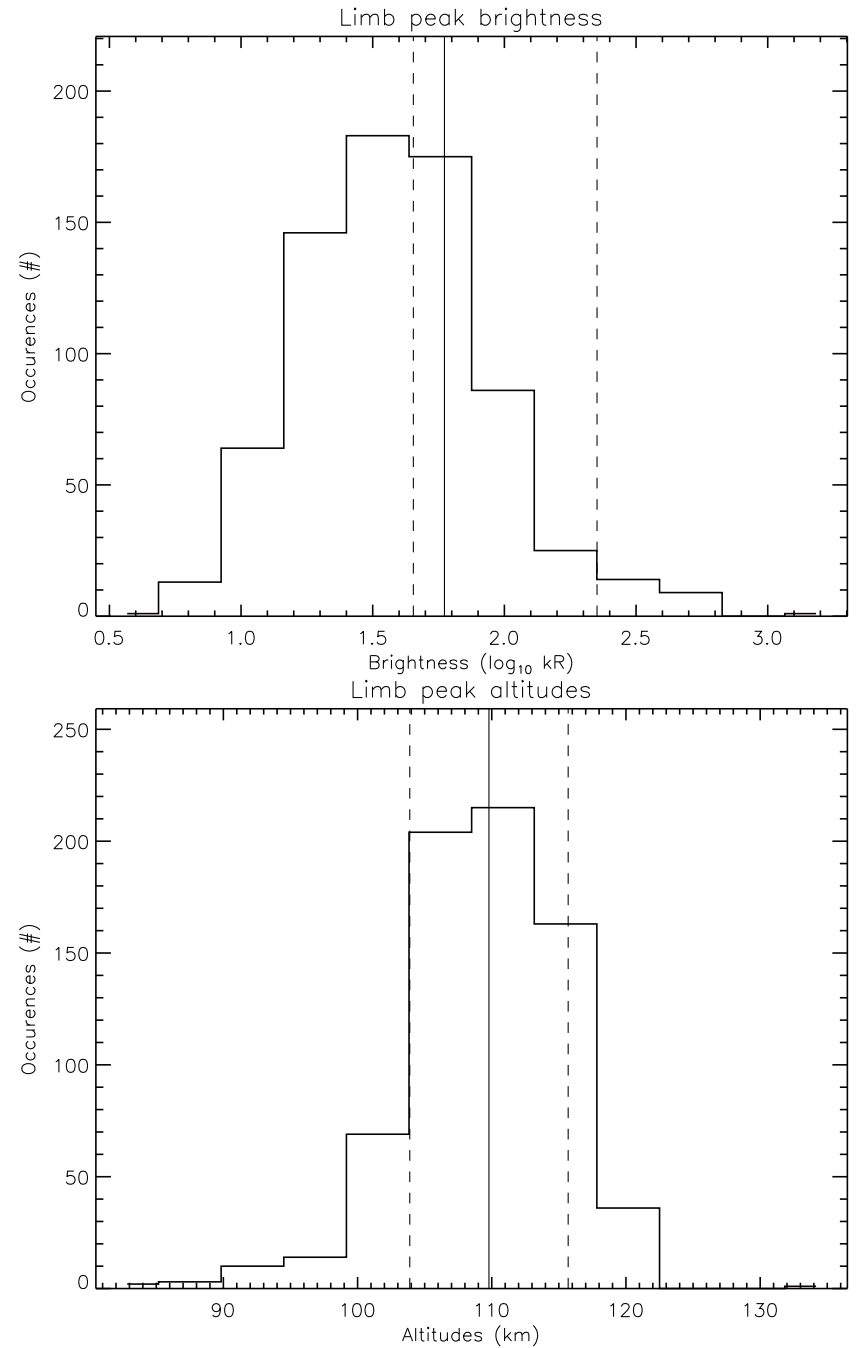

Figure 3: Up panel: limb profiles peak brightness distribution from data. The brightness axis is logarithmic. Down panel: distribution of the limb profiles peak altitudes from data. In both panels, the solid vertical line represent the mean values while the dashed lines represent the standard deviation of the mean value. 


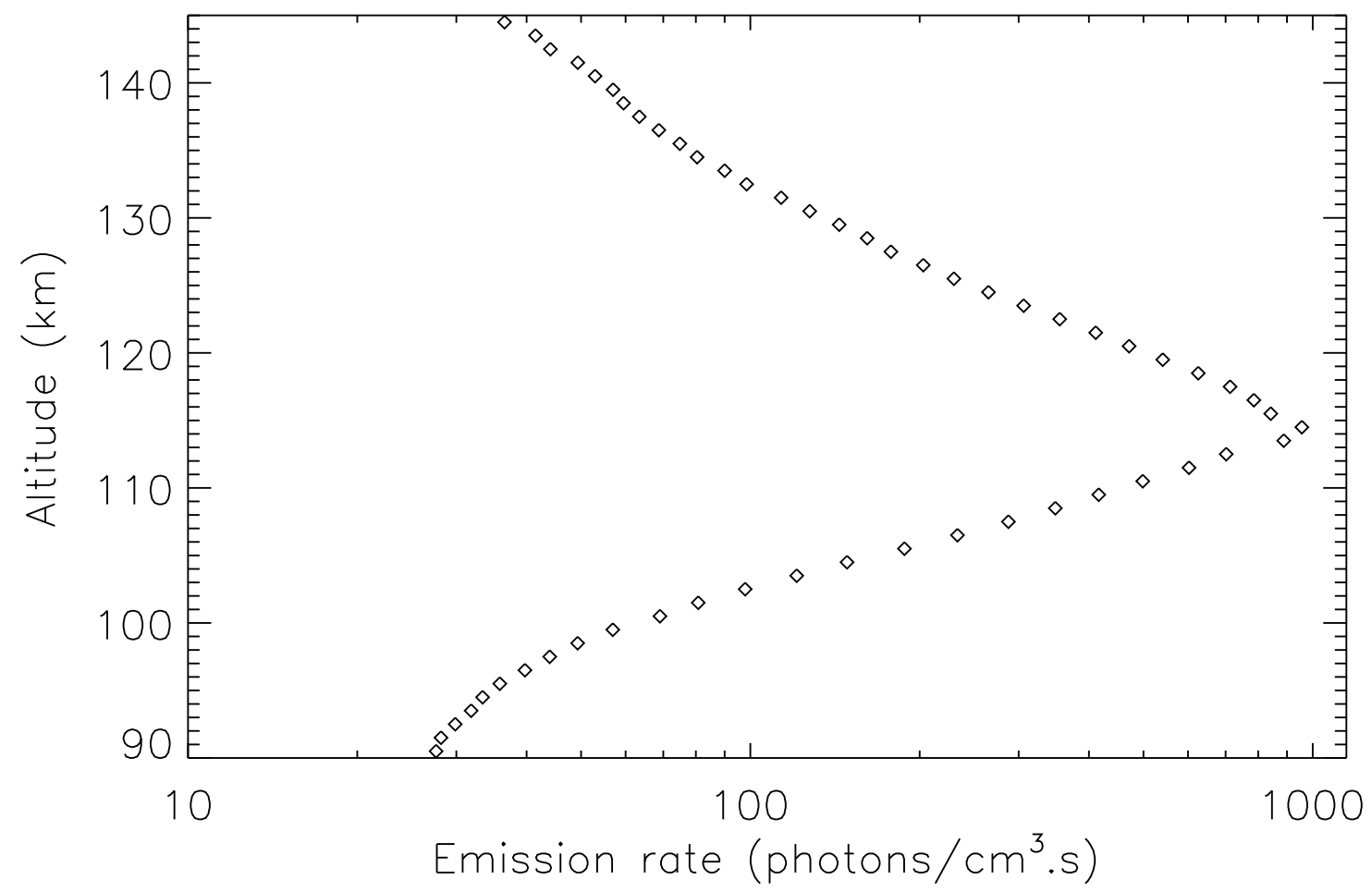

Figure 4: Mean Volume Emission Rate (VER) profile from the nitric oxide ultraviolet airglow emission SPICAV data. 

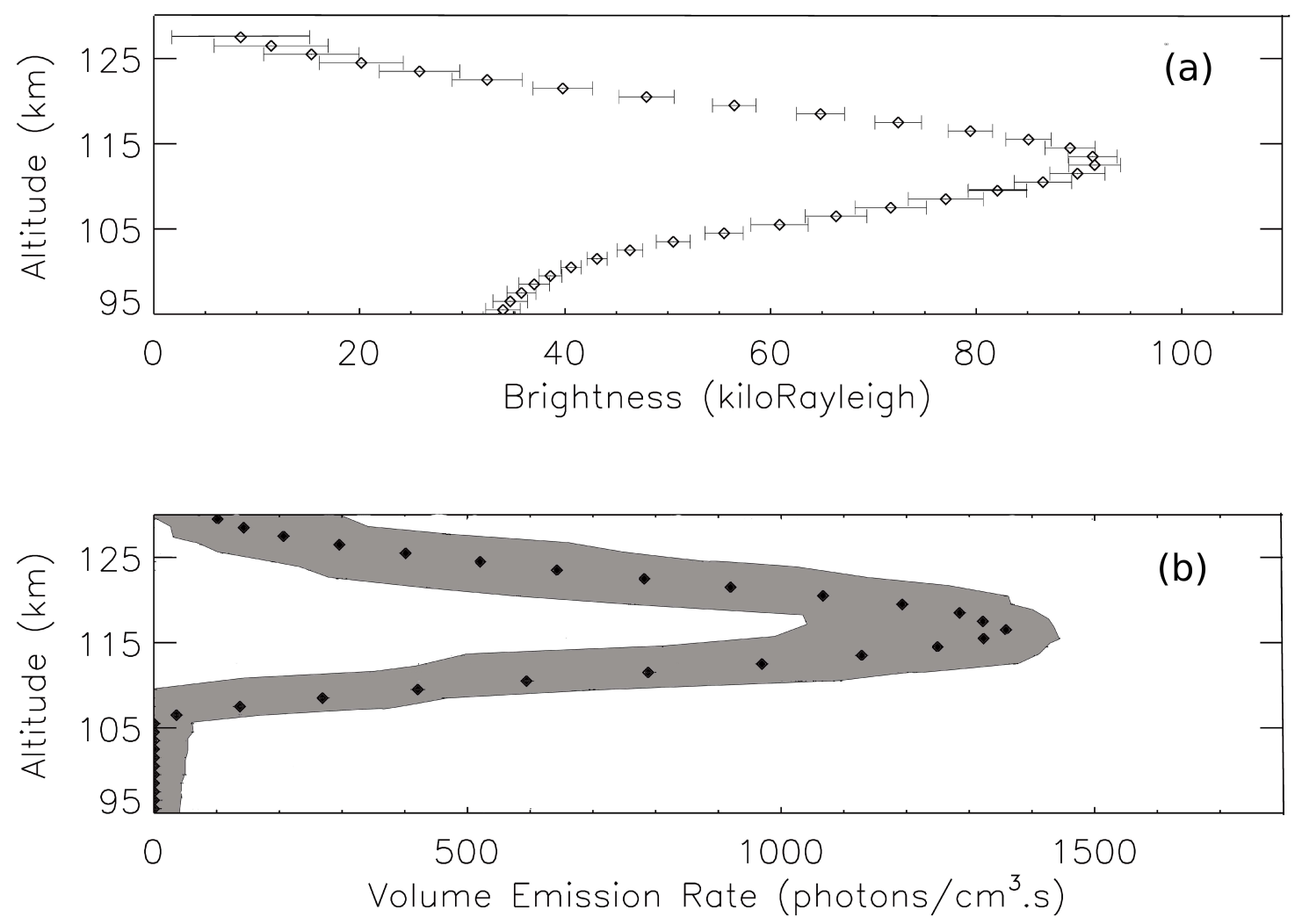

Figure 5: Panel (a): deconvolved limb profile obtained during Venus Express orbit 324. The solid lines represent the instrumental error bars on the intensity. Panel (b): 1,000 profiles are generated: at each data point, a normal distribution centered on the observed intensity and whose standard deviation is equal to the local error bar represents the random noise. The black diamonds represent the inversion of the observed limb profile. The grey zone illustrates the one-sigma scatter resulting from the inversion of the other 1,000 profiles. 

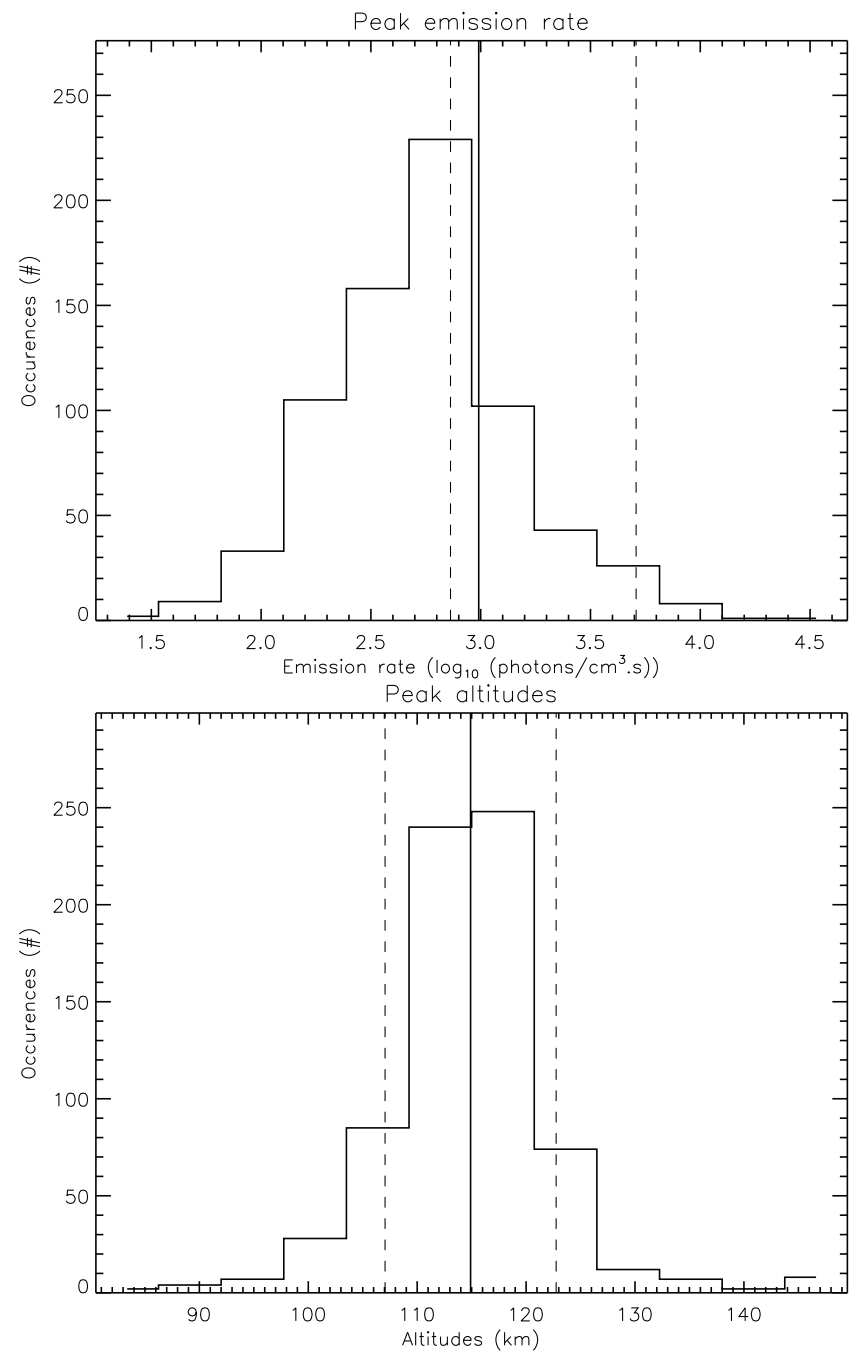

Figure 6: Up panel: limb profiles peak VER distribution from the data. The brightness distribution shows a Gaussian-like shape on a logarithmic scale. Down panel: altitude distribution of the peaks of VER. 

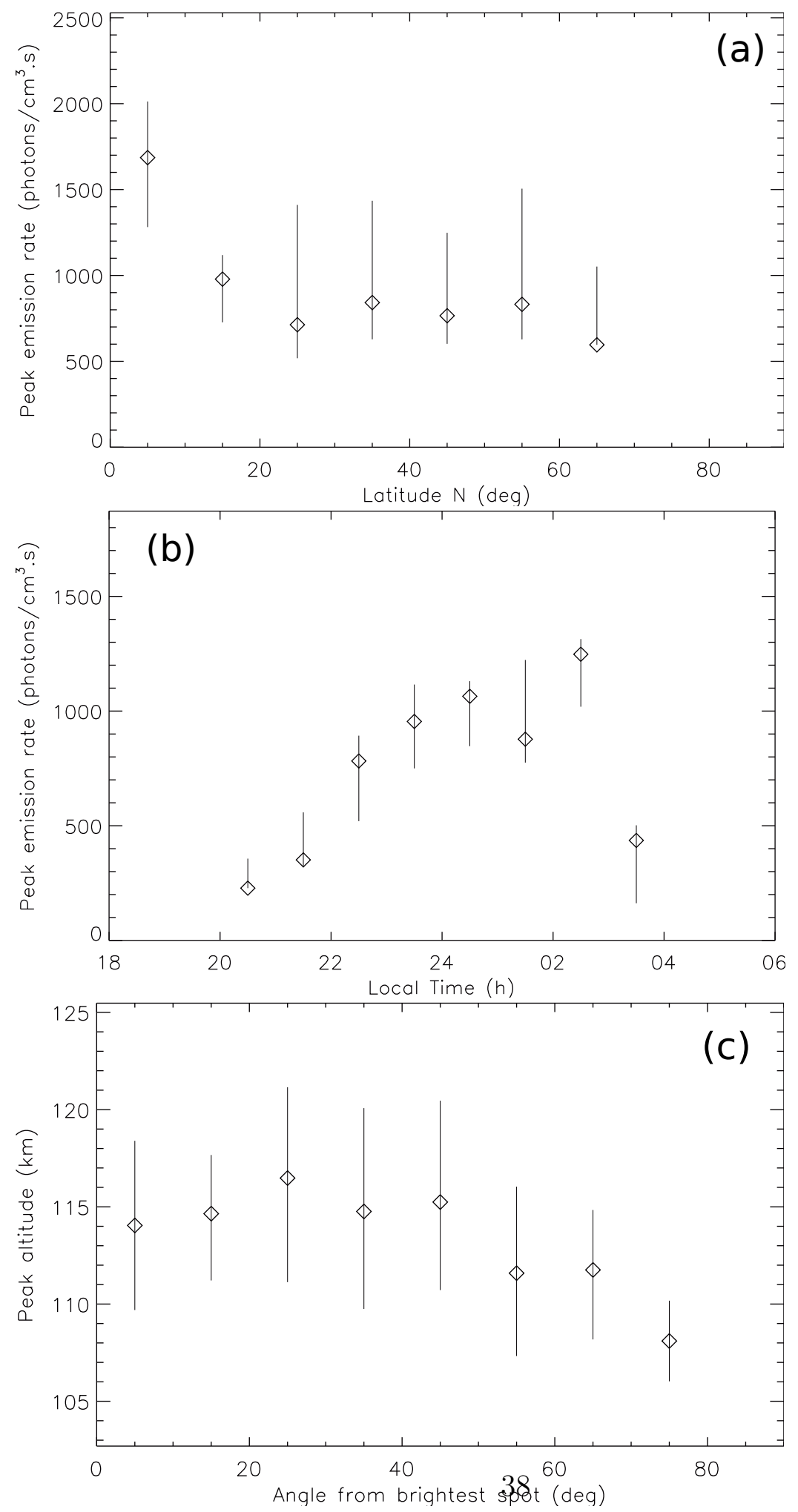

Figure 7: (a) Peak VER calculated from the database versus northern latitude. The vertical bars correspond to a one-sigma standard deviation. (b) Peak VER versus local time. (c) Mean peak altitude versus the angle from the statistical bright spot (ABS). Peak altitude has a mean value of $115 \mathrm{~km}$ in the range $0^{\circ}$ to $45^{\circ}$ and then decrease to $108 \mathrm{~km}$ at $75^{\circ}$. 


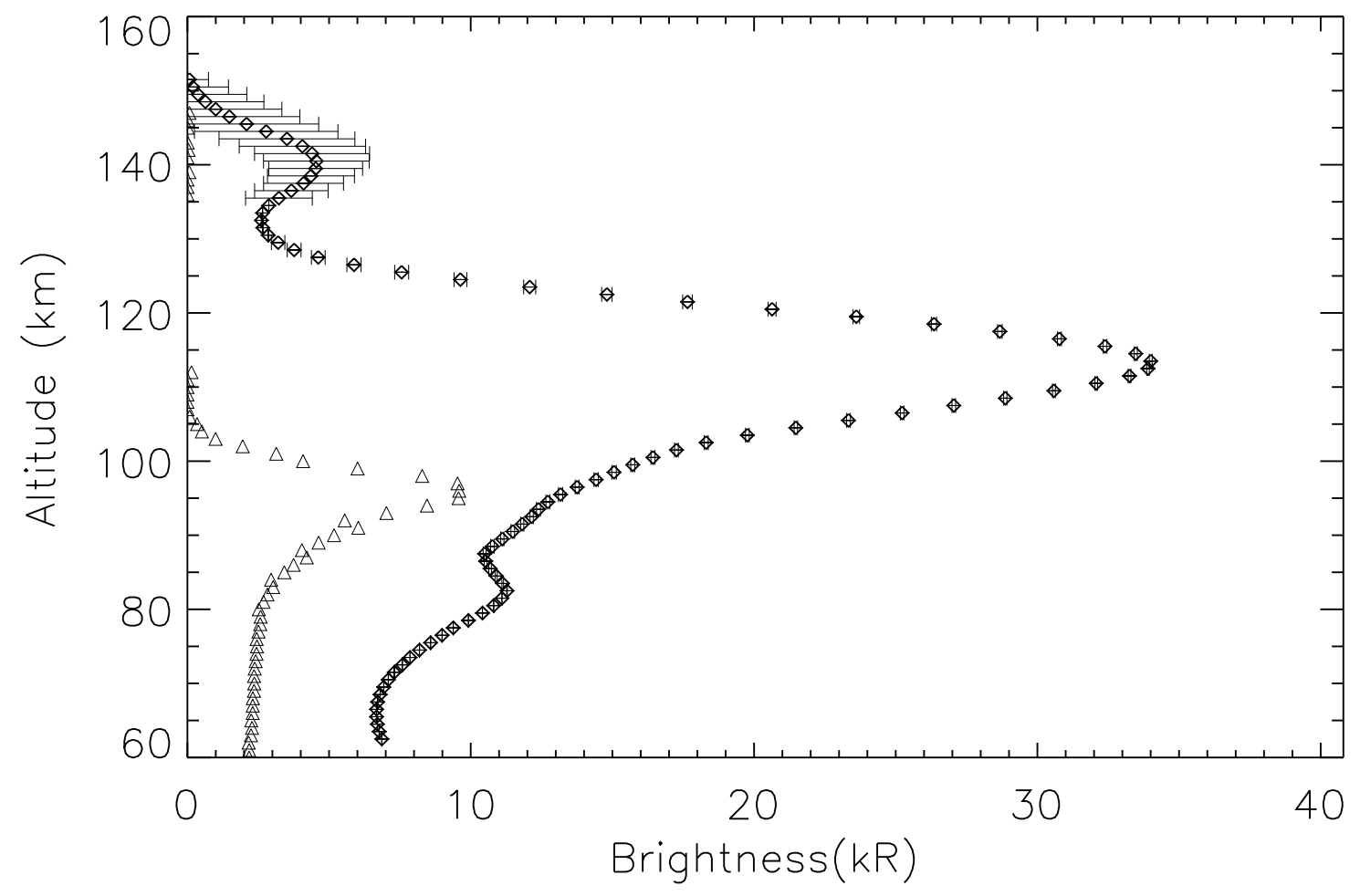

Figure 8: Diamonds: deconvolved profile of NO airglow obtained with SPICAV where multiple peaks in the NO limb profiles are observed. Triangles represent a quasi-simultaneous measurement of the $\mathrm{O}_{2}\left(a^{1} \Delta\right)$ limb profile where only one peak appears. The $\mathrm{O}_{2}\left(a^{1} \Delta\right)$ limb profile is scaled by a factor $10^{6}$. Diamonds come from SPICAV data while triangles come from VIRTIS data. 


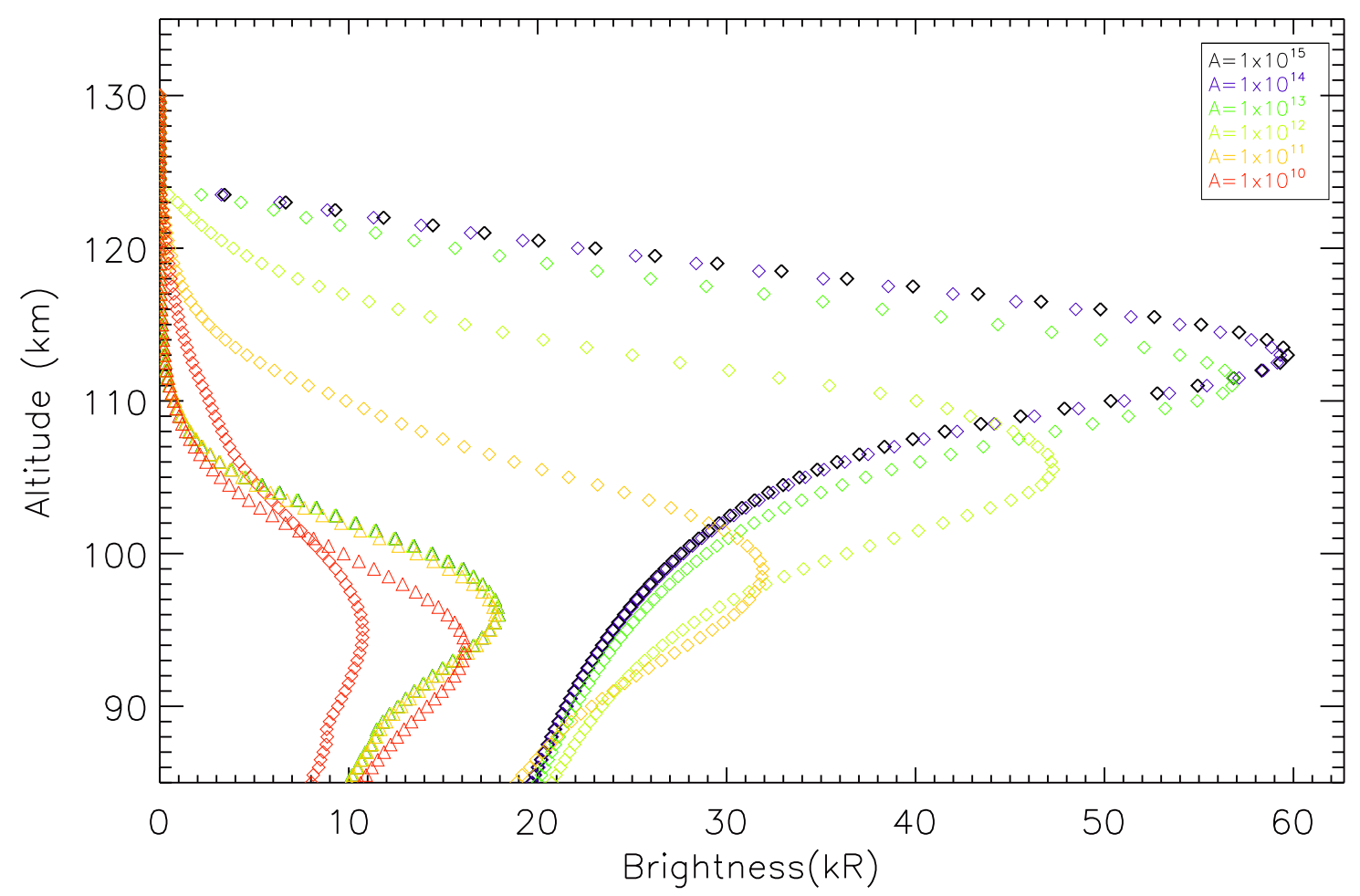

Figure 9: $\mathrm{NO}$ (diamonds) and $\mathrm{O}_{2}$ (triangles) airglow brightness profiles from the onedimensional chemical-diffusive model for six different values of the coefficient A ranging from $\mathrm{A}=1 \times 10^{10}$ in dark blue to $1 \times 10^{15}$ in red with a step factor of $10 . \mathrm{O}_{2}$ intensity values are divided by a factor 1000 . The $\mathrm{O}$ and $\mathrm{CO}_{2}$ density profiles are taken from Soret et al. (2012). 


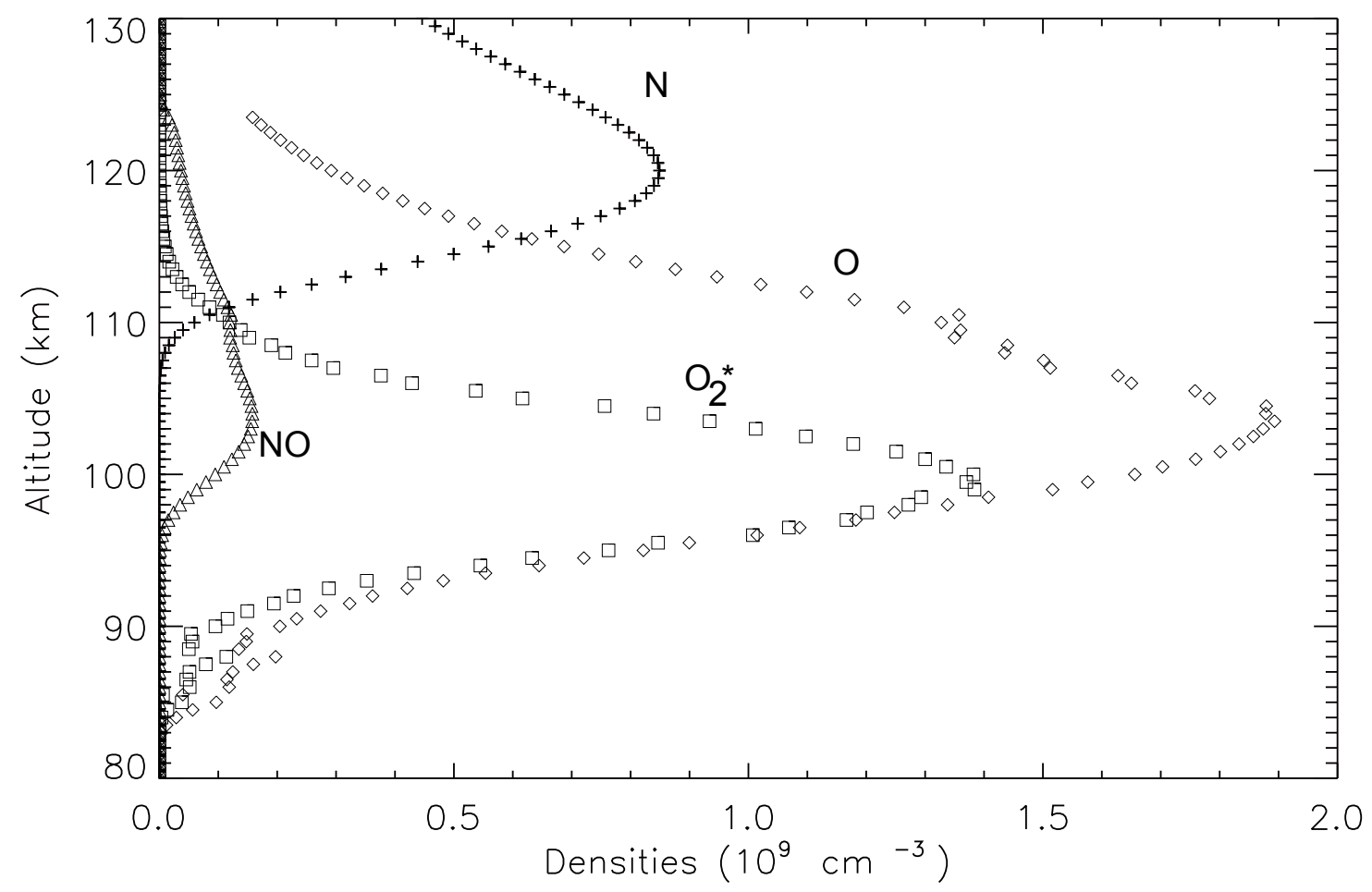

Figure 10: $\mathrm{N}$ (pluses), $\mathrm{O}$ (diamonds), $\mathrm{NO}$ (triangles) and $\mathrm{O}_{2}\left(a^{1} \Delta\right)$ (squares) density profiles used or obtained from the model. The $\mathrm{O}$ density profile is fixed and taken from Soret et al. (2012), while other species density profiles are calculated by the 1-D model. The $\mathrm{O}$ density profile is divided by a factor 100 and the NO density profile is multiplied by a factor 100 . 